\title{
Dura Mater: Anatomy and Clinical Implication
}

\author{
Mehmet Ünal1*, Ahmet Burak Sezgin² \\ ${ }^{1}$ Flex \& Form, Kocaeli, Turkey \\ ${ }^{2} \mathrm{ABS}$ holistik sağlık, İstanbul, Turkey \\ Email: ^fztmehmet6@gmail.com, ahmetburaksezgin@gmail.com
}

How to cite this paper: Ünal, $M$. and Sezgin, A.B. (2021) Dura Mater: Anatomy and Clinical Implication. Journal of Behavioral and Brain Science, 11, 239-247. https://doi.org/10.4236/jbbs.2021.1110019

Received: August 25, 2021

Accepted: October 5, 2021

Published: October 8, 2021

Copyright $\odot 2021$ by author(s) and Scientific Research Publishing Inc. This work is licensed under the Creative Commons Attribution International License (CC BY 4.0).

http://creativecommons.org/licenses/by/4.0/

\begin{abstract}
The dura mater is of similar embryological origin to the fascial organ. It contains several fibroblasts which make the dura mater a flexible structure. Dura mater is the outermost of the three layers of meninges, a thick and rigid inelastic membrane that covers the brain and spinal cord and that is impermeable to the cerebrospinal fluid. The cranial dura mater in certain respects differs anatomically from the dura material in the spinal cord, and it is important to classify them separately. This article reviews the anatomical structure of spinal and cranial dura mater and its anatomy with muscle, fascia, bone structure and ligaments. Dura mater is a structure in the body that is connected with systemic functions.
\end{abstract}

\section{Keywords}

Dura Mater, Osteopathy, Physiotherapy

\section{Introduction}

The dura mater is of the same embryological origin as the fascial system. It contains several fibroblasts which make it a flexible structure for the dura mater [1]. Dura mater is the outermost of the three meninges layers, a thick and dense inelastic membrane surrounding the brain and spinal cord and impermeable to the cerebrospinal fluid (CSF). In certain ways, the cranial dura mater varies anatomically from the spinal dura mater, and it is important to identify them separately. However, both forms are part of one complete membrane, which is continuous at the magnum foramen. The dural system is responsible for promoting and sustaining brain functions in tandem with the CSF and acts as a means of protection in the event of mechanical trauma. Mechanical forces directed at the skull are overcome by shock-free absorption, due to bone elasticity, skull pillar structure, nasal sinuses, and viscerocranium attachment to neurocranium [2]. This article reviews the anatomical structure of the spinal and cranial duramate, 
as well as its connections with the myofascial system and the spine.

\section{Review}

\subsection{Spinal Dura Mater}

The spinal dura mater (SDM) is an inelastic collagen fiber tube that forms a loose sheath around the spinal medulla and closely matches the vertebral canal curvature. CSF, which relies on hydrostatic, respiratory, and pulsating influences, keeps the dura under stress [3]. The dura stretches from the occipital bone foramen magnum to the sacral canal and is invested with the spinal cord filum terminale at S3 level, which blends with the coccyx periosteum. A potential cavity, the subdural area, separates the spinal dura mater from the arachnoid mater. However, both membranes are usually in close contact with each other, except where a minute quantity of CSF separates them. The dura mater is divided into three layers: an outer fibroelastic layer of flattened cells with thin and long cell extensions toward the epidural space; a middle fibrous layer; and an inside boundary cell layer with extracellular spaces, few cell junctions, and no extracellular collagen. There are several elastic fibers inside the dura, suggesting significant versatility and elasticity during motion and postural changes. The deforming forces applied to the spinal cord and meninges are distributed inside the extradural space through the subarachnoid space and the fibroadipose tissue. During the transition from the foramen magnum to the vertebral canal, two dural layers can be distinguished: the outer, periostal layer which ceases at the foramen magnum, with the periosteum lining the vertebral canal taking its place, and the inner layer, the true SDM. The epidural area, which is not present within the cranium, separates these two layers and makes gliding movements between the dura and the spine (Figure 1) [4].

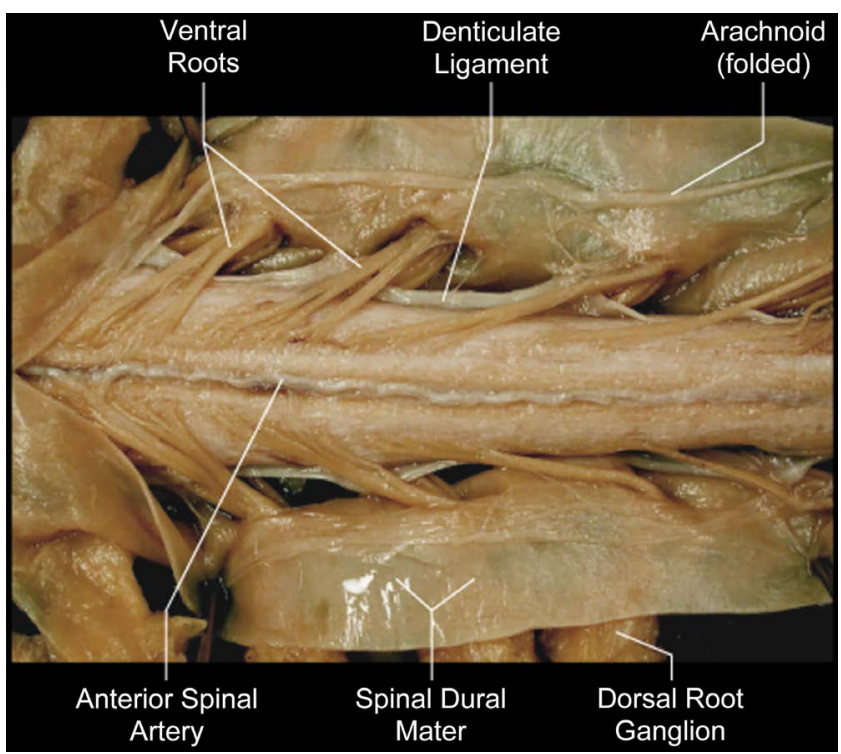

Figure 1. Spinal dura mater

http://biodrawing.com/Neurology modules/NervousSystemSite/Neuroanatomy/figures. 
The posterior longitudinal ligament boundaries the anterior epidural space; the lateral medial aspect of the pedicles and intervertebral foramine; and the posterior aspect of the laminae and ligamentum flava boundary. Superior to this, the dura combines with the foramen magnum periosteum. In the cervical and lumbar regions the thickness of the dura mater is greater than in the thoracic region. Spinal dura mater fascial relationships and attachments are listed in more detail below. Such structures facilitate the movement of the dural tube inside the spinal canal and prevent the dura or spinal cord from having to fold or other injury-causing mechanisms [5].

\subsection{Connections with Muscles and Ligaments}

The ligamentum craniale durae matris spinalis (CDMS ligament) was originally described by Von Lanz as fibrous strands extending from the dura mater to the occipital bone, the posterior longitudinal ligament and the transverse atlas ligament. Subsequently, the CDMS attaches the atlas arch and axis, the occipital squama periosteum, and laterally the atlanto-occipital and atlantoaxial joints [3]. More fibers originating from the flaval ligaments between C1 - C2 and C2 - C3 have been identified and other dura-connected fibers have been found between the $\mathrm{C} 2$ and $\mathrm{C} 3$ arches. Rutten and colleagues believe that during movement portions of the CDMS ligament act as a tensioner of the upper cervical vertebral column [6].

The SDM is also bound by connective tissue bands to the posterior atlanto-occipital (PAO) membrane at the atlanto-occipital joint, which generates a network and is where the rectus capitis posterior minor (RCPmi) is also detectable [7] [8]. The myodural relation between the RCPmi and the SDM can prevent the folding of the SDM towards the spinal canal, which tends to occur during neck and head extension. The obliquus capitis inferior (OCI) is connected to the posterolateral part of the dura mater and the rectus capitis posterior majör (RCPma) spreads through the atlantoaxial interspace to the posterior dura mater [9] [10].

The myodural bridge between the SDM and the suboccipital muscles has significant clinical importance in that severe stresses can be transmitted to the dura across the myodural bridge, which is expressed as cervicogenic headache [8] [9] [10] [11].

Attachments have been found between the posterior SDM and the nuchal ligament at the first and second vertebrae stages, which is important in head rotational movements [12] [13].

A connection between the flaval ligament and the SDM was found at the level of the vertebral bodies in the upper and lower cervical spines. Other direct attachments at the level of C7/T1 were also described [6] [14] [15]. The rear SDM is anchored through the posterior cervical epidural ligaments to the flaval ligament. Anterior displacement of the dura is indicated in the absence or malfunction of certain ligaments, which may contribute to flexion myelopathy [16].

On the SDM is attached the superficial layer of the posterior longitudinal li- 
gament (PLL) [3]. Similarly, the ligaments of Hofmann are found between the dura and the PLL's superficial layer [10] [17] [18]. Sometimes the PLL's superficial layer is more used as a protective membrane for the soft structures within the vertebral canal than as a typical ligament [15] [19]. Trolard's ligaments are also called the ventromedian ligaments associated with the posterior longitudinal ligament (PLL). These are found in the lower lumbar and sacral spine, between the dura and the vertebral bodies and arc [20]. The trousseaux fibreux of Soulié consists of a network of strong bundles which support the anterior epidural venous plexus and link the dura mater with the posterior longitudinal ligament and the periosteum [21].

Denticulate ligaments are fibrous structures that extend the entire length of each side of the spinal cord, separating the ventral from the spinal nerve dorsal roots. The toothlike processes of these ligaments are attached to the dura mater. Extension and flexion of the spine is transmitted via the denticulate ligaments by the SDM to the pia mater, with the greater part of the forces being transmitted directly to the spinal cord via cranial and caudal attachments of the dura. The rhomboid halter is a thin, diamond-shaped connective tissue plate that is attached to the dura mater via the upper toothlike processes of the denticulate ligaments [22]. It has been proposed that the rhomboid halter holds the cranial area of the spinal cord and the lower medulla oblongata segregated during neck flexion from the axis dens, the ligamentous apparatus, and the vertebral arteries [23]. Forestier's opercula is situated at the level of each intervertebral foramen, which indicates a relation between the span of spinal nerve coverage and the periosteum of the individual vertebra [21].

\subsection{Blood Supply}

Vascularisation The direction of the arteries of the spinal cord is very complex. Paired posterior spinal arteries and anterior spinal artery have SDM. Venous drainage occurs outside the vertebral column and the segmental veins through venous plexuses. Such valveless plexus veins have particular physiological significance. They can interact with the lumbar and intercostal veins, and with venous plexuses in the nuchal zone, which enables the venous blood to be drained multidirectionally without obstruction. Innervation The SDM is sparsely innervated as opposed to the cranial dura mater [24].

\subsection{Innervation}

The innervations are especially less dense dorsally than ventrally. Dorsal dural nerves are derived from the ventral dural plexus, which is linked to the sinuverterbal nerves, the nerve plexus of the posterior longitudinal ligament, and the nerve plexus of segmental artery radicular branches [25].

\section{Cranial Dura Mater}

The dura mater cranial lines the skull's interior. It is composed of two parts, the 
outer layer of endosteal and the inner layer of meninges. Both layers are closely related, except when sinuses are formed for venous blood passage. The cranial dura mater consists of white fibrous tissue and a particular layer of flattened fibroblastic cells with no extracellular space and collagen, which can be found at the gap between dura mater and arachnoid material. The dura mater's outer surface closely adheres to the bone's inner surfaces, with these adhesions being most prominent at the base of the skull and opposite the sutures. The dura's outer surface is rough and fibrillated while the inner surface is smooth and endothelium-lined (Figure 2). The dura mater continues at the skull's outer surface through the specific foramina that reside at the skull's base. Its fibrous layer forms sheaths for the nerves leaving the cranium, thereby passing through the foramina. At the foramen magnum the dura is fused to the bone, which is continuous with the dura mater spinal. The scalp skin and the dura are connected by emissary veins. The dura is especially flat in the ethmoid bone cell areas, the tegmentum, and the sigmoid sinuses. The dura inner meningeal layer is structurally weaker than the exterior endosteal layer [26].

An adult's dura can withstand greater force than a neonate's dura [27]. According to Arbuckle a specific fiber structure allows different forces to be transmitted by the cranial and spinal dura [28]. In specified classes, these so-called "stress fibers" are structured: horizontal, vertical, transverse and circular. This path of fibers in the cranial dura mater can result from mechanical forces during embryonic development, when stress forces align collagenous fibers [29].

\subsection{Falx Cerebri}

The falx cerebri is a small, sickle-shaped dura mater fold that descends vertically into the longitudinal fissure between the hemispheres of the cerebrum. It is attached to the ethmoid's crista galli at the front, and is connected to the tentorium cerebelli at the back. Its lower margin is free and concave, and contains the lower saggital sinus, whereas the upper margin is attached to the inner surface of the midline of the skull, reaching back to the inner occipital protuberance [30] [31] [32].

\subsection{Tentorium Cerebelli}

The tentorium cerebelli is a dural fold lying in the axial plane which divides the cranial cavity into supratentorial and infratentorial compartments. It protects the superior cerebellum surface, and supports the brain's occipital lobes. Previously, the deep tentorial knotch, which enables contact between the supratentorial and infratentorial compartments, connects to clinoid processes and forms the lateral portion of the cavernous sinüs. Subsequently it is connected to the inner surface of occipital bones by its convex edge, and the transverse sinuses are enclosed there. It connects anteriorly to the petrous portions of the temporal bones, enclosing the petrosal sinuses above. The tentorium is also attached to the falx cerebri which places the straight sinus at its junction [32] [33]. 


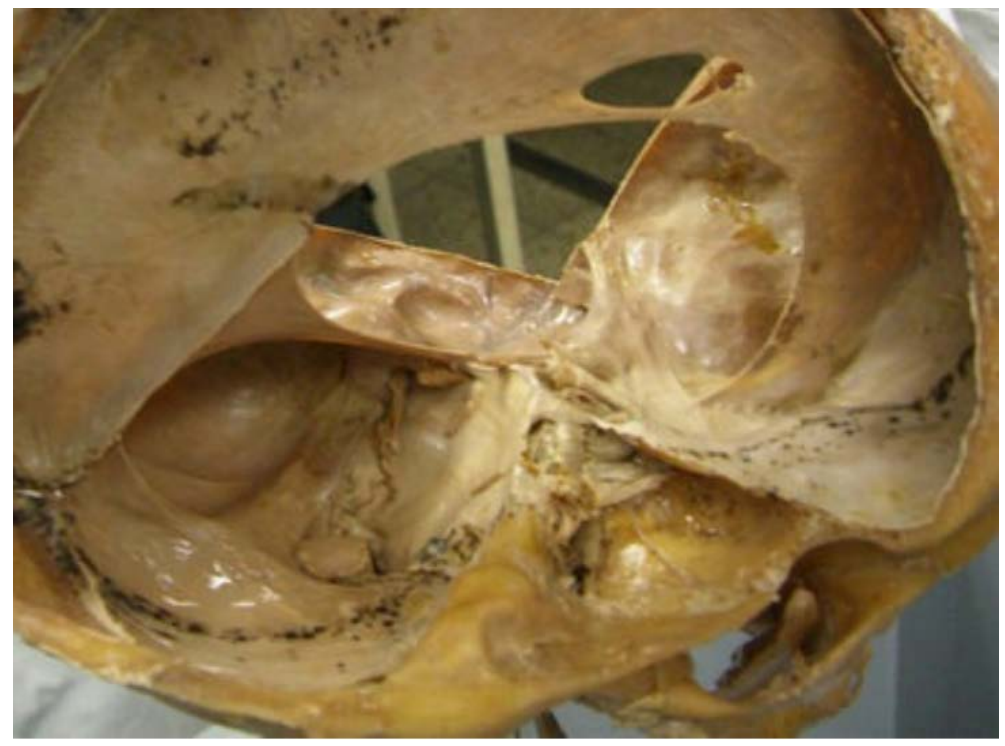

Figure 2. Cranial Dura Mater Dr. med. Dieter G. Thomas, D.O.M., gradierwerk, Multisensorische Privatpraxis für Osteopathie \& Physiotherapie, Bad Nenndorf/Germany.

\subsection{Falx Cerebelli}

The falx cerebelli is a small fold of the dura over the posterior cranial fossa floor. It separates the hemispheres of the two cerebellars. Superior to that, the falx cerebelli is attached to the tentorium cerebelli, and inferior to the foramen magnum. It then connects to the occipital bone's internal occipital crest, which includes the occipital sinus [33].

\subsection{Blood Supply}

The supply of dural blood usually concerns the outer layer of the dura, since the inner layer does not require a significant supply of blood. There are numerous arteries providing the dura mater. In the anterior cranial fossa are situated the anterior meningeal branches of the anterior and posterior ethmoidal and internal carotid, and a branch of the middle meningeal artery. The middle cranial fossa comprises frontal and parietal branches of the middle meningeal artery, which passes through the foramen spinosum into the middle cranial fossa; the peripheral meningeal and pharyngeal arteries; and branches of the internal carotid arteries. Those in the posterior cranial fossa are the occipital meningeal branches, the posterior meningeal branch of the vertebral artery, occasional meningeal branches of the ascending pharyngeal artery, and a branch of the middle meningeal artery. Venous drainage from the cranial dura mater occurs with the diploic veins through anastomosis, and ends in the various sinuses. The middle meningeal veins open up into the pterygoid plexus, into the maxillary vein, or into the lower ophthalmic vein and cavernous sinus through the pterygoid plexus. Meningeal veins drain into the sinuses, directly or indirectly through the jugular vein [1] [34]. 


\subsection{Innervation}

The innervation of the upper part of the dura mater is primarily provided by the meningeal branches of the trigeminus and vagus nerves, with the upper cervical spinal nerves in the lower part being inerved. The anterior cranial fossa provides nerve supply through an ophthalmic division of the trigeminal nerve; the nasociliar branch; and anterior and posterior ethmoidal nerves. The middle cranial fossa is inerved by meningeal branches of the trigeminal nerve's ophthalmic, maxillary, and mandibular divisions. The second and third cervical sections provide the innervation of the posterior cranial fossa. Therefore, a tension in the dura mater area is transferred to the muscle and fascia system through these connections (e.g. headache may occur due to trigeminal nerve activation) [1] [35].

\section{Conclusion}

The dura mater is of similar embryological origin to the fascial organ. It contains several fibroblasts which make the dura mater a flexible structure. This article discussed the dura mater anatomy and its relationship with muscle, bone structure, ligament and fascia. The limiting area of the study was that anatomical studies on this subject were not included in recent years, so new information could not be included. The aim of the study is to focus on the relationship of the dura mater with the fascial system.

\section{Funding Sources}

The author received no specific funding for this work.

\section{Author Contributions}

All stages of this article were carried out by the responsible author.

\section{Conflicts of Interest}

The authors have no conflicts of interest to declare.

\section{References}

[1] Adeeb, N., Mortazavi, M., Tubbs, S. and Cohen-Gadol, A. (2012) The Cranial Dura Mater: A Review of Its History, Embryology, and Anatomy. Child s Nervous System, 28, 827-837.

[2] Neuhuber, W.L. (1998) Der kraniozervikale übergang: entwicklung, gelenke, muskulatur und innervation. In: Hülse, M., Neuhuber, W.L., Wolff, H.D., Eds., Der kraniozervikale Übergang, Springer, Berlin, 11-31. https://doi.org/10.1007/978-3-642-58853-2 2

[3] Von Lanz, T. (1929) Über die Rückenmarkshäute. I. Die konstruktive Form der harten Haut des menschlichen Rückenmarkes und ihre Bänder. Wilhelm Roux’ Archiv für Entwicklungsmechanik der Organismen, 118, 252-307. https://doi.org/10.1007/BF02108876

[4] Vandenabeele, F., Creemers, J. and Lamprichts, I. (1996) Ultrastructure of the Hu- 
man Spinal Arachnoid Mater and Dura Mater. Journal of Anatomy, 189, 417-430.

[5] Westbrook, J. (2012) Anatomy of the Epidural Space. Anaesthesia and Intensive Care Medicine, 13, 551-554. https://doi.org/10.1016/j.mpaic.2012.08.020

[6] Rutten, H., Szpak, K., Van Mameren, H., Ten Holter, J. and De Jong, J.C. (1997) Anatomic Relation between the Rectus Capitis Posterior Minor Muscle and the Dura Mater (Letter; Comment). Spine, 22, 924-925. https://doi.org/10.1097/00007632-199704150-00018

[7] Kahkeshani, K. and Ward, P.J. (2012) Connection between the Spinal Dura Mater and Suboccipital Musculature: Evidence for the Myodural Bridge and a Route for Its Dissection-A Review. Clinical Anatomy, 25, 415-422. https://doi.org/10.1002/ca.21261

[8] Hack, G.D., Koritzer, R.T., Robinson, W.L., Hallgren, R.C. and Greenman, P.E. (1995) Anatomic Relation between the Rectus Capitis Posterior Minor Muscle and the Dura Mater. Spine, 20, 2484-2485.

https://doi.org/10.1097/00007632-199512000-00003

[9] Pontell, M.E., Scali, F., Enix, D., Battaglia, P.J. and Marshall, E. (2013) Histological Examination of the Human Obliquus Capitis Inferior Myodural Bridge. Annals of Anatomy, 195, 522-526. https://doi.org/10.1016/j.aanat.2013.04.013

[10] Scali, F., Pontell, M.E., Welk, A.B., Malmstrom, T.K., Marshall, E. and Kettner, N.W. (2012) Magnetic Resonance Imaging Investigation of the Atlanto-Axial Interspace. Clinical Anatomy, 26, 444-449. https://doi.org/10.1002/ca.22094

[11] Scali, F., Marsili, E.S. and Pontell, M.E. (2011) Anatomical Connection between the Rectus Capitis Posterior Major and the Dura Mater. Spine, 36, E1612-E1614. https://doi.org/10.1097/BRS.0b013e31821129df

[12] Humphreys, B.K., Kenin, S., Hubbard, B.B. and Cramer, G.D. (2003) Investigation of Connective Tissue Attachments to the Cervical Spinal Dura Mater. Clinical Anatomy, 16, 152-159. https://doi.org/10.1002/ca.10109

[13] Dean, N.A. and Mitchell, B.S. (2002) Anatomic Relation between the Nuchal Ligament (Ligamentum Nuchae) and the Spinal Dura Mater in the Craniocervical Region. Clinical Anatomy, 15, 182-185. https://doi.org/10.1002/ca.10001

[14] Kubo, Y., Waga, S., Kojima, T., Matsubara, T., Kuga, Y. and Nakagawa, Y. (1994) Microsurgical Anatomy of the Lower Cervical Spine and Cord. Neurosurgery, 34, 895-902. https://doi.org/10.1227/00006123-199405000-00017

[15] Hayashi, K., Yabuki, T., Kurokawa, T., Seki, H., Hogaki, M. and Minoura, S. (1977) The Anterior and the Posterior Longitudinal Ligaments of the Lower Cervical Spine. Journal of Anatomy, 124, 633-636. https://doi.org/10.1148/124.2.501

[16] Shinomiya, K., Dawson, J., Spengler, D.M., Konrad, P. and Blumenkopf, B. (1996) An Analysis of the Posterior Epidural Ligament Role on the Cervical Spine Cord. Spine, 21, 2081-2088. https://doi.org/10.1097/00007632-199609150-00005

[17] Von Lüdinghausen, M. (1967) Die Bänder und das Fettgewebe des Epiduralraumes. Anatomischer Anzeiger, 121, 294-312.

[18] Tagil, S.M., Ozcakar, L. and Bozkurt, M.C. (2005) Insight into Understanding the Anatomical and Clinical Aspects of Supernumerary Rectus Capitis Posterior Muscles. Clinical Anatomy, 18, 373-375. https://doi.org/10.1002/ca.20106

[19] Loughenbury, P.R., Wadhwani, S. and Soames, R.W. (2006) The Posterior Longitudinal Ligament and Peridural (Epidural) Membrane. Clinical Anatomy, 19, 487-492. https://doi.org/10.1002/ca.20200

[20] Barbaix, E., Girardin, M.D., Hoppner, J.P., Van Roy, P. and Clarijs, J.P. (1996) An- 
terior Sacrodural Attachments-Trolard's Ligaments Revisited. Manual Therapy, 1, 88-91. https://doi.org/10.1054/math.1996.0255

[21] Liem, T. (2017) Anatomy of the Dura Mater. In: Liem, T., Tozzi, P. and Chila, A., Eds., Fascia in the Osteopathic Field, Handspring Publishing, Vermont.

[22] Rossitti, S. (1993) Biomechanics of the Pons-Cord Tract and Its Enveloping Structures: An Overview. Acta Neurochirugica, 124, 144-152. https://doi.org/10.1007/BF01401138

[23] Breig, A. (1978) Adverse Mechanical Tension in the Central Nervous System: An Analysis of Cause and Effect; Relief by Functional Neurosurgery. John Wiley \& Sons, New York.

[24] Hu, J.W., Vernon, H. and Tatourian, I. (1995) Changes in Neck Electromyography Associated with Meningeal Noxious Stimulation. Journal of Manipulative and Physiological Therapeutics, 18, 577-581.

[25] Groen, G.J., Baljet, B. and Drukker, J. (1998) The Innervation of the Spinal Dura Mater: Anatomy and Clinical Implications. Acta Neurochirurgica, 92, 39-46. https://doi.org/10.1007/BF01401971

[26] Haines, D.E., Harkey, H. and Mefty, O. (1993) The "Subdural" Space: A New Look at an Outdated Concept. Neurosurgery, 32, 111-120. https://doi.org/10.1227/00006123-199301000-00017

[27] Ziablov, V.I., Shapovalov, I., Toskin, K.D., Tkach, V. and Zhebrovskiŭ, V.V. (1982) Structure and Physicomechanical Properties of the Human Dura Mater from the Age Aspect. Arkhiv anatomii, gistologii i embriologii, 82, 29-36.

[28] Arbuckle, B.E. (1994) The Selected Writings of Beryl E. Arbuckle, DO, FACOP. American Academy of Osteopathy, Indianapolis, 74-91.

[29] Hamann, M.C., Sacks, M.S. and Malinin, T.I. (1998) Quantification of the Collagen Fibre Architecture of Human Cranial Dura Mater. Journal of Anatomy, 192, 99-106.

[30] Jinkins, J.R. (2000) Atlas of Neuroradiologic Embryology, Anatomy, and Variants. Lippincott Williams \& Wilkins, Philadelphia.

[31] Herle, P. (2012) Basic and Clinically Relevant Anatomy: A Guide for Students and House Surgeons. Pradyumna Herle, Melbourne.

[32] Standring, S. (2008) Gray's Anatomy: The Anatomical Basis of Clinical Practice. 40th Edition, Elsevier, Singapore.

[33] Singh, I. (1987) Textbook of Anatomy: Vol III. Jaypee Brothers Medical Publishers, New Delhi.

[34] Andres, K.H., Schmidt, R.F., et al. (1987) Nerve Fibres and Their Terminals of the Dura Mater Encephali of the Rat. Anatomy and Embryology, 175, 289-301. https://doi.org/10.1007/BF00309843

[35] Lv, X., Wu, Z. and Li, Y. (2014) Innervation of the Cerebral Dura Mater. The Neuroradiology Journal, 27, 293-298. https://doi.org/10.15274/NRJ-2014-10052 